\title{
BIOGENIC SILVER NANOPARTICLES MEDIATED BY BROUSSONETIA PAPYRIFERA: ANTICANCER AND ANTIMICROBIAL ACTIVITY AGAINST PATHOGENIC ORGANISMS
}

\author{
VASANTH $\mathbf{N}^{1 *}$, MELCHIAS $\mathrm{G}^{2}$, KUMARAVEL $\mathrm{P}^{3}$ \\ ${ }^{1}$ Department of Botany, St. Joseph's College (Autonomous), Tiruchirappalli, Tamil Nadu, India. ${ }^{2}$ Department of Botany, School of \\ Biological Sciences, Associate Professor of Botany, St. Joseph's College (Autonomous), Tiruchirappalli, Tamil Nadu, India. ${ }^{3}$ Department of \\ Biotechnology, Vysya College, Salem, Tamil Nadu, India. Email: vasanthresearchsjc@gmail.com
}

Received: 22 January 2017, Revised and Accepted: 07 February 2017

ABSTRACT

Objective: To evaluate the potential aspects of biologically synthesized silver nanoparticles (AgNPs) mediated by Broussonetia papyrifera against the human pathogens. The same is acknowledged to have high efficiency in the field of Pharmaceutical industry.

Methods: The $1 \mathrm{mM}$ of $\mathrm{AgNO}_{3}$ is prepared and mixed with an appropriate volume of plant extract and reaction volume was made up to 100 ml. The physical characterization of AgNPs was done. The antimicrobial activity was done against dread pathogens. Cytotoxic activity of the AgNPs was investigated against breast and lung cancer cell lines.

Results: The field emission scanning electron microscopy and energy dispersive X-ray spectroscopy of the microscopic level showed the particle surface measurements around 44-50 nm. The X-ray powder diffraction investigations are being an evidence for the crystalline structure of the AgNPs with $30 \mathrm{~nm}$. The bacterial pathogen Rhodococcus rhodochrous showed the maximum zone of inhibition (11.8 \pm 0.447$)$. The A549 human lung cancer cell line and MCF-7 human breast cancer cell line were tested against the toxicity of AgNPs. The toxicity of AgNPs was valued and corresponding inhibitory concentration for lung cancer (A549) is $12.95 \pm 0.05 \mu \mathrm{g} / \mathrm{mL}$ and breast cancer (MCF-7) is $10.75 \pm 0.05 \mu \mathrm{g} / \mathrm{mL}$, respectively.

Conclusion: This research denotes that biomolecules derived AgNPs have a larger impact as antimicrobials in the biomedical field. Since the aggressive chemicals are not involved AgNPs production, these bio-substances can of alternative medicine to resistant once. The in-vitro experiments exhibit the therapeutic effect of this AgNPs based on the ambient concentration on the process.

Keywords: Cancer activity, Antimicrobial agents, Resistance, Silver nanoparticles.

(C) 2017 The Authors. Published by Innovare Academic Sciences Pvt Ltd. This is an open access article under the CC BY license (http://creativecommons. org/licenses/by/4. 0/) DOI: http://dx.doi.org/10.22159/ajpcr.2017.v10i5.17237

\section{INTRODUCTION}

The research on silver nanoparticles (AgNPs) and their characterization is an emerging field of nanotechnology for the last two decades, due to their huge applications biomedical fields. The innovative discipline globally enkindles the interest confined in the size of the object is nanotechnology. The intellect anticipation in life sciences has directly interrelated to additional branches like biomedical and Biotechnology. The plant derived nanomaterials are specific in its nature such as size, distribution, and morphology [1,2]. The NPs from the metallic compounds are whose synthesis contributes toward larger volume of NPs. Among every part of the metal-based nanomaterials, Ag gives the impression to be better, because it's specificity in terms of properties, often gives positive significance in the field of medical industry. The antimicrobials potential of AgNPs from plant-based compound has high volume, in terms of its therapeutic aspects [3]. And specific to this study, NPs also inhibit the cancer cells, which is one the most important and leading research today. The disease cancer is one of the dread diseases of the humankind. It has been projected that 14 million new cancer cases and 8.2 million cancer-associated deaths were reported in 2012. There is country which has annual disease rate is high Africa, Asia, and Central and South America represent 70\% [4,5]. In the direction of specificity about the plant resource; Broussonetia papyrifera is economically useful and medicinally has a wide range of applications. It is a fast growing deciduous plant and native to Asia; the bark and inner part of the plant are economically sound [6,7]. The leaves of this plant have anticancer efficacy, in which the volume of the plant part is higher than the AgNPs which shows the inhibitory concentration $\left(\mathrm{IC}_{50}\right)$ at the higher rate. In biosynthesis method, using bacteria, fungi, and plants are already well-documented [8]. The water-soluble organics in the plant bio molecules are sole responsible for the reduction of silver ions to nano-sized Ag particles.

Plant-mediated synthesis of NPs is an approach that intercom- nests nanotechnology and plant biotechnology [9]. Plant extract has been found optional source to chemical and physical methods. Plants mediated nanoparticles can be advantageous over other biological processes by eradicating the complex progression of maintaining cell cultures [10]. Therefore, this study aims at characterization and evaluation of antimicrobial and anticancer efficiency studies of AgNPs from B. papyrifera, ultimately a constructive approach cum application to various branches of medical industry.

\section{METHODS}

\section{Chemicals}

The $\mathrm{AgNO}_{3}$ was used as a substrate for the synthesis of AgNPs. The $\mathrm{AgNO}_{3}$ was purchased from $\mathrm{Hi}$ media Laboratories Pvt. Ltd., Mumbai, India. The water has been obtained through glass double distillation [11].

\section{Collection and authentication of plant}

The plant B. papyrifera (L.) Vent. - Authenticated by Botanical Survey of India (BSI) Coimbatore - 641003 India. The reference number is BSI/SRC/5/23/2015/Tech.2500. This particular plant was collected from Indian Institute of Science (IISc) campus, Bengaluru, (KA) India.

\section{Preparation of plant extracts}

To prepare an aqueous extract of B. papyrifera the leaf part (20 g) washed thoroughly with distilled water and dried for 5 days at room 
temperature. Then, the leaves were powdered, and $1 \mathrm{~g}$ of leaf powder was taken in a $250 \mathrm{ml}$ Erlenmeyer flask with $100 \mathrm{ml}$ sterile distilled water. The sample was boiled for 5 minutes at $70^{\circ} \mathrm{C}$. The filtrate, thus, obtained was stored at $4^{\circ} \mathrm{C}$ and used further studies.

\section{Synthesis of AgNps}

A $5 \mathrm{ml}$ aliquot of the plant extract was mixed with $95 \mathrm{ml}$ of aqueous $1 \mathrm{mM}$ silver nitrate (AgNO3) for reduction of the silver nitrate into Ag+ ions and kept at room temperature for up to $24 \mathrm{hrs}$. About 10 minutes after mixing the color of the solution began changing into reddish brown indicating the formation of AgNPs.

\section{Characterization of AgNPs}

Field emission scanning electron microscopy (FESEM)

The FESEM was performed on the AgNPs to characterize the mean particle size and the morphology/shape/topography of the AgNPs. The powder and freeze-dried samples of the AgNPs were sonicated; a small drop of this sample was placed on glass slide and allowed to dry. A thin layer of platinum was coated to make the samples conductive. FESEM studies were performed using Hitachi model S3000H, Hitachi Ltd, Tokyo, Japan [12].

\section{Energy dispersive $X$-ray spectroscopy (EDAX)}

The system for EDAX, namely, Bruker offers a powerful range for energy dispersion of AgNPs The new generation of QUANTAX EDAX features the XFlash ${ }^{\circledR} 6$ detector series with active areas from 10 to $100 \mathrm{~mm}^{2}$. $10,30,60$, and $100 \mathrm{~mm}^{2}$ active area detectors offer ideal solutions for micro- and nano-analysis. Energy resolutions for detectors are usually specified in accordance with ISO 15632:2002 [13].

\section{$X$-ray powder diffraction (XRD)}

XRD studies were conducted using XPERTPRO multipurpose X-ray diffractometer procured from the Netherlands, using $\mathrm{Cu}$ Ko radiation with a wavelength of $1.540 \AA$. With the model of D8-A25, the XRD at is high (up to $1200^{\circ} \mathrm{C}$ ) in air or vacuum with double laser alignment system. The dried powder of AgNPs was further analyzed under X'Pert Pro X-ray diffractometer operated at a voltage of $40 \mathrm{kV}$, and a current of $30 \mathrm{~mA}$ with $\mathrm{Cu} \mathrm{K} \alpha$ radiation in $\theta-2 \theta$ configurations and its crystalline domain size was calculated from the width of the XRD peaks using the Scherrer's formula, $D=0.94 \lambda / \beta \operatorname{Cos} \theta$.

Where, $\mathrm{D}$ - is the average crystalline domain size perpendicular to the reflecting planes, $\lambda$ - is the X-ray wavelength, $\beta$ - is the full width at half maximum, $\theta$ - is the diffraction angle. Hence, from XRD, the crystallite size of AgNPs can be found out using the Scherrer's formula [14].

\section{Antimicrobial activity \\ Antibacterial assay}

Nutrient Agar/medium (pH 7.4 \pm 2 ) was poured (10-15 ml) into each sterile Petri plates. After solidification, $100 \mu \mathrm{l}$ of suspension containing $10^{8} \mathrm{CFU} / \mathrm{ml}$ of each test microbe was spread over the agar plates. The sterile filter paper discs ( $6 \mathrm{~mm}$ in diameter) were impregnated with AgNPs $(30 \mu \mathrm{g} /$ disc) placed on the inoculated agar. Negative control $\mathrm{AgNO}_{3}(30 \mu \mathrm{g} / \mathrm{disc})$ was prepared using the disc. Moreover, then streptomycin $(30 \mu \mathrm{g} / \mathrm{disc})$ was used as a positive reference control to determine the sensitivity of the bacterial species. The inoculated plates were incubated at $37^{\circ} \mathrm{C}$ for $24 \mathrm{hrs}$. This activity was evaluated by measuring the zones of inhibition against the test organisms. Each assay was conducted in triplicate.

\section{Anticancerous activity}

\section{Cell culture}

The A549 human lung cancer cell line and MCF-7 human breast cancer cell line were obtained from National Center for Cell Science, Pune, India. The cells were cultured in DMEM high glucose medium (Sigma-Aldrich, USA), supplemented with $10 \%$ fetal bovine serum (Gibco), and $20 \mathrm{~mL}$ of penicillin/streptomycin as antibiotics (Gibco), in 96 -well culture plates, at $37^{\circ} \mathrm{C}$ in a humidified atmosphere of $5 \%$ $\mathrm{CO}_{2}$ in a $\mathrm{CO}_{2}$ incubator (Thermo scientific, USA). All experiments were performed using cells from passage 15 or less.

\section{Cell viability assay}

The complexes, silver nitrate, AgNPs, B. papyrifera, were first dissolved in dimethyl sulfoxide (DMSO) to make a stock. These stock solutions were diluted separately with media to get various concentrations of the complex. $200 \mu \mathrm{l}$ of these samples were added to wells containing $5 \times 10^{3}$ A549 and MCF-7 cells per well. DMSO solution was used as the solvent control. After $24 \mathrm{hrs}, 20 \mu \mathrm{l}$ of MTT solution ( $5 \mathrm{mg} / \mathrm{mL}$ in PBS) was added to each well, and the plate was wrapped with aluminum foil and incubated for $4 \mathrm{hrs}$ at $37^{\circ} \mathrm{C}$. The purple formazan product was dissolved by addition of $100 \mu \mathrm{l}$ of DMSO to each well. The absorbance was monitored at $570 \mathrm{~nm}$ (measurement) and $630 \mathrm{~nm}$ (reference) using a 96-well plate reader (Bio-Rad, iMark, USA). Data were collected for three replicates each and used to calculate the respective mean. The percentage inhibition was calculated, from this data, using the formula:

Mean of absorbance of untreated cells (control)

- Mean of absorbance of treated cells

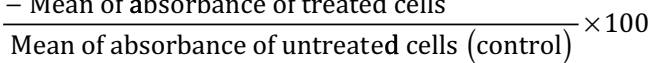

\section{Acridine orange (AO) and ethidium bromide (EB) staining}

Apoptotic morphology was investigated by AO/EB double staining method as described by Spector et al. [15] with some modifications. Briefly, the cells treated with $\mathrm{IC}_{50}$ concentration of compounds for $24 \mathrm{hrs}$. After incubation, the cells were harvested and washed with cold PBS. Cell pellets were resuspended and diluted with PBS to a concentration of $5 \times 10^{5}$ cells $/ \mathrm{mL}$ and mixed with $25 \mu \mathrm{l}$ of AO/EB solution $(3.8 \mu \mathrm{M}$ of $\mathrm{AO}$ and $2.5 \mu \mathrm{M}$ of EB in PBS) on clean microscope slide and immediately examined under fluorescent microscope (Carl Zeiss, Axioscope 2 plus) with UV filter (450-490 nm). 300 cells for each sample were scored for viable, apoptotic or necrotic by staining the nucleus structure and membrane integrity and the percentage of apoptotic and necrotic cells were calculated accordingly.

\section{Statistical analysis}

The correlation coefficient was measured for the zone of inhibition of AgNPs, plant extracts and antibiotics. The standard deviation, z-test, and t-test are calculated to analyze the data statistically.

\section{RESULTS AND DISCUSSION}

\section{Biosynthesis of nanoscale silver particles}

The leaf extracts of B. papyrifera and aqueous $\mathrm{AgNO}_{3}(1 \mathrm{mM})$ solution were altered from yellowish green to reddish brown, the final color becomes visible immediately. The complete reaction mixture turned to brown color within 10 minutes of reaction setup. The AgNPs produced by the B. papyrifera leaf were observed to be very stable in the solution, even 3 months after their synthesis, which authenticate as source plant as biomaterials for the synthesis of nano-sized Ag particles.

\section{FESEM}

The FESEM image shows (Fig. 1) the morphology of the nanoparticles. This particular component refers to the NPs size distribution in aqueous suspension. The report indicates that encapsulate NPs are incredibly observed with its topography using imaging property [16]. The surface of the synthesized NPs shows size between ranges from 20 to $50 \mathrm{~nm}$, and same results were also reported for phytosynthesized AgNPs [17]. The obtained results give an idea about that the particles size ranges from 44 to $50 \mathrm{~nm}$. The AgNPs shows the particles are embedded and varying in size and shape; the average of this mean size is similar to some of the results reported earlier. The AgNPs are polydispersed with various sizes and having the spherical shape the NPs have illustrate without the agglomeration process in the morphology structure. Therefore, the ultrastructural morphological features can be obtained through the FESEM image microscopy. 


\section{EDAX}

The energy dispersive spectrum of biogenic AgNPs shows (Fig. 2) the metallic compound in the formation of NPs synthesis. Metallic AgNPs generally show a typically strong signal peak at $3 \mathrm{keV}$, due to surface plasmon resonance [18-20]. Corresponding results of AgNPs shows the maximum the component involved for the NPs synthesis. And Ag metallic compound contributed a lot for the NPs formation. Among the other consequent the Ag hold around 55\% of the metallic presence. Along with the Ag having the maximum; the other precursors are 0-8\%, C- $6 \%$, CL- $17 \%$, Ca- $20 \%$, Na-11\%, Mg- $12 \%$, and Si-14\%.The highintensity signals pertaining to the results shows the presence of mere AgNPs. Thus, EDAX has the credibility in presenting metallic compound role for the formation of AgNPs. Hence, 55\% of Ag metal in the sample that only indicates the pure form Ag in the process of AgNPs.

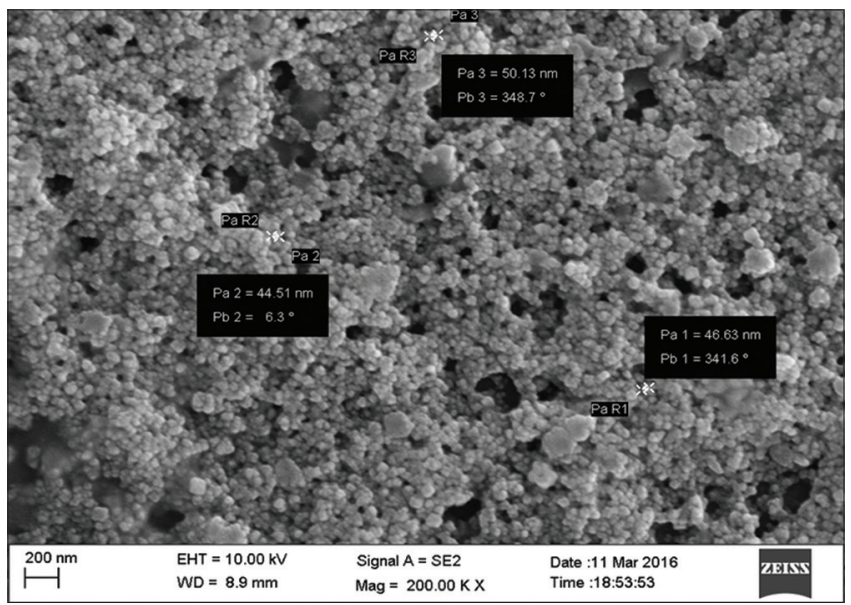

Fig. 1: Field emission scanning electron microscopy images of developed silver nanoparticles from Broussonetia papyrifera

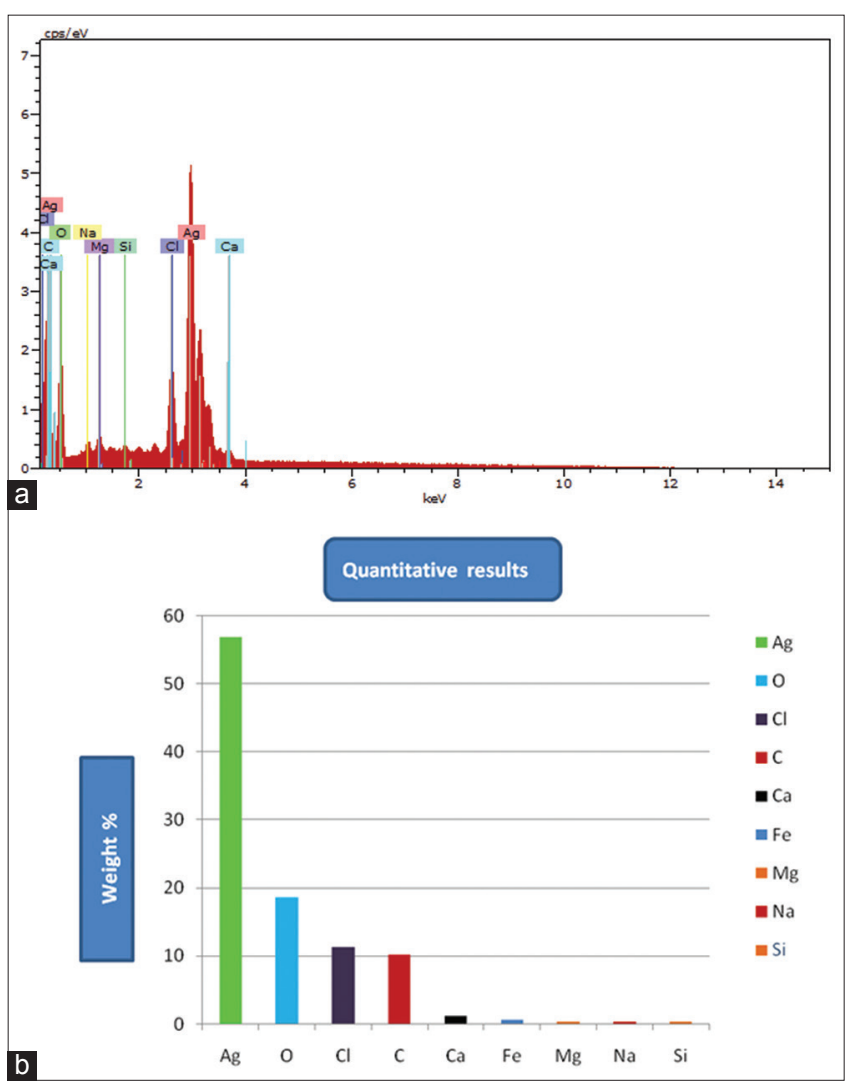

Fig. 2: (a and b) Energy dispersive X-ray spectroscopy spectrum showed elemental signals of silver
XRD

The XRD pattern of AgNPs shows Fig. 3 and Table 1 the patterns corresponds to the recorded using the XRD results. The phase purity and composition of AgNPs has shown the better results. The obtained peaks are indexed as plans of face-centered cubic (FCC) silver by the comparison process with joint committee of powder diffraction standards (JCPDS) data. The results of XRD analysis shows the diffraction peaks at $38.07,32.23,27.75,46.17$, and 23.49 can assign to various planes of the AgNPs are compared. The results are in good agreement with reference of FCC structure from JCPDS card No-087-0720. The resulted peaks show that crystalline structure of NPs. There are some additional unassigned peaks due to the impurities [21]. The obtained result of this pattern shows the crystalline structure of NPs is $30 \mathrm{~nm}$. The results are correlating with the present literature [22,23].

\section{Anticancer analysis \\ MTT reduction assay}

The AgNPs are day by day spreading its creditability due to the impact in various fields such as biomedical industry. Since the size and shape have the main focus, it really adapted by many research community around the world. To test the toxicity of AgNPs on cancer cells, the MTT reduction assay was performed. The cytotoxic of AgNPs against cancer cell are due to Physico-chemical interaction of silver atoms with the functional groups of cellular proteins as well as nitrogen bases and phosphate elements of DNA [24]. The observed $\mathrm{IC}_{50}$ values for $24 \mathrm{hrs}$ reveal that all the complexes exhibit a lower range of cytotoxicity. The ability of the complexes to kill the cancer cells at $24 \mathrm{hrs}$ incubation vary as silver nitrate, AgNPs, B. papyrifera. (Table 2) the results from this MTT assay indicate that the complexes silver nitrate, AgNPs are highly cytotoxic against MCF-7 cancer cells and lung cancer cell line (A549) similar results correlates with these findings [25]. The cytotoxicity of AgNPs shows that the increase with the concentration of AgNPs leads to the increase in the inhibition rate. In similar report, human breast cancer cell showed $100 \%$ cell death at $50 \mathrm{mg} / \mathrm{ml}$ concentrations of AgNPs, and in vice versa, the mushroom derived AgNPs showed cytotoxicity at a lower concentration. The results are at similarity toward the many conclusions on cytotoxicity of AgNPs [26,27].

\section{AO and EB staining}

The most important characteristics of apoptosis are morphological changes during cell death (Fig. 4). The details below represents that AO/EB double-stained A549 human lung cancer cell line (Fig. 5) and breast cancer cell line MCF 7 (Fig. 6) treated with test substances $24 \mathrm{hrs}$ underwent both early apoptosis (cells with red arrows) and late apoptosis. The control or viable cells shows green fluorescence and normal cell features of uniform chromatin with an intact cell membrane, whereas, the early apoptosis cells showed bright green region with yellowish green nuclear fragmentation and membrane bubbles and apoptotic bodies outside. The late apoptosis cells exhibited orange-yellow or red nuclei with condensed or fragmented chromatin. The results demonstrate that all substances induce the majority of cell death through apoptosis mode and very fewer in necroses for $24 \mathrm{hrs}$ treatment. Chromatin condensation and fragmentation were majorly observed in silver nitrate, AgNPs treated cells. The colloidal Ag also inhibits the cell growth by apoptosis in MCF-7 human breast cancer cell lines [28]. The AgNPs for 48 hrs MCF-7 show the apoptotic characters, namely, cell shrinkage, nuclear condensation, and fragmentation, whereas in the control the cells exhibited nuclear architecture. The morphological features are because of caspase cascades, that responsible for the DNA repair [29].

\section{Antimicrobial assay}

The AgNPs synthesized by B. papyrifera were found to have the highest antimicrobial activity against pathogenic microorganism compared with silver nitrate and streptomycin antibiotics (Table 3) and (Figs. 7 and 8). Bacterial strains such as Rhodococcus rhodochrous, Vibrio cholera, Staphylococcus aureus, Pseudomonas aeruginosa, and Escherichia coli, however, these AgNPs get a hold to the cell membrane and also penetrated inside the bacteria. The bacterial membranes include 


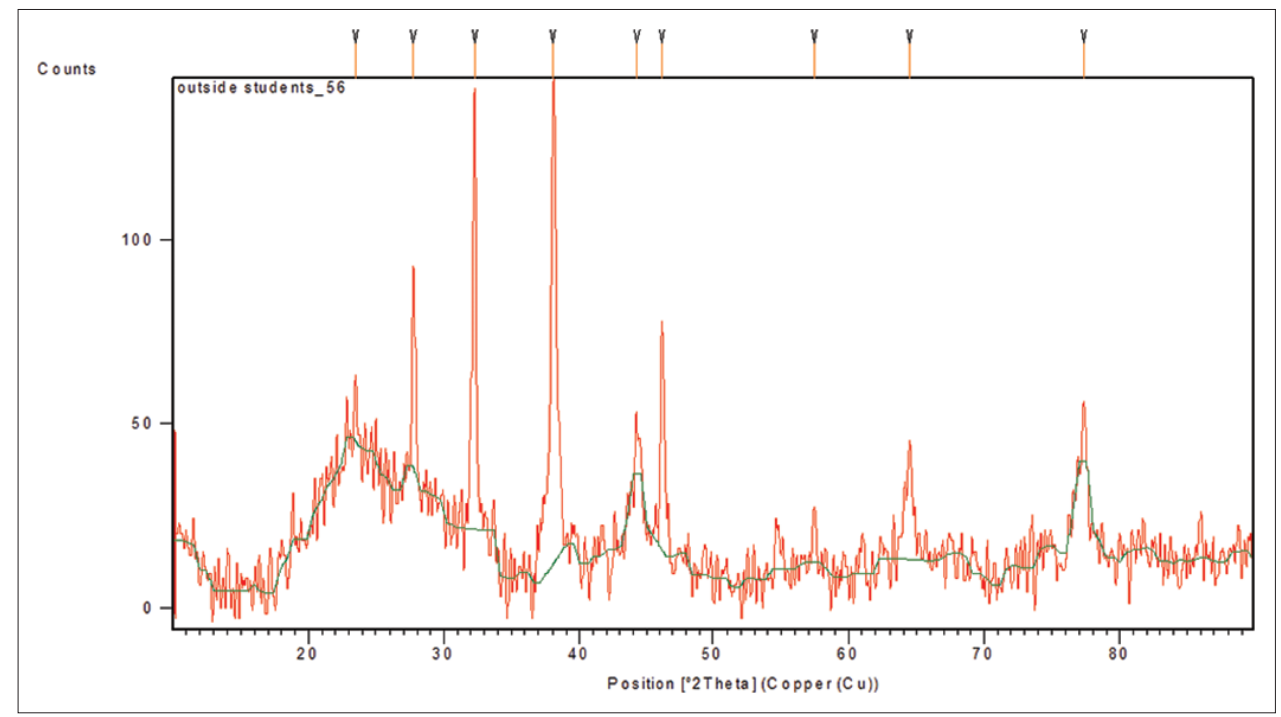

Fig. 3: X-ray powder diffraction patterns of biosynthesized silver nanoparticles

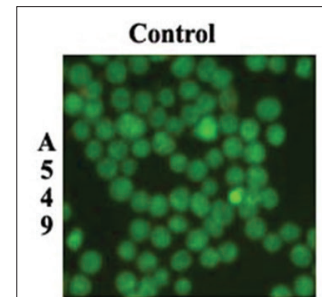

Silver Nitrate

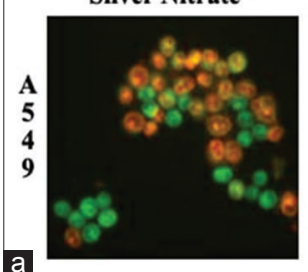

a
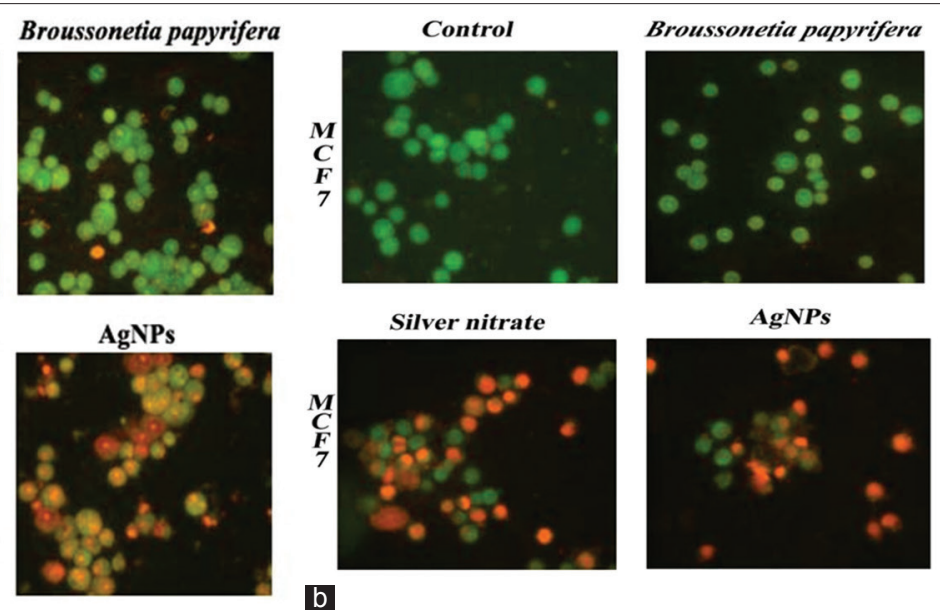

b

Fig. 4: (a and b) Acridine orange/ethidium bromide control, silver nitrate, Broussonetia papyrifera, and silver nanoparticles. Green color cells are live cells and red color cells showing apoptotic morphology

Table 1: The crystalline structure of measured particle size

\begin{tabular}{llllll}
\hline Pos. (2Th.) & Height (cts) & FWHM (2Th.) & d-spacing ( $(\AA)$ & Relative interval (\%) & Particle size (nm) \\
\hline 38.0755 & 130.28 & 0.3680 & 2.36345 & 100.00 & 23 \\
32.2371 & 118.38 & 0.2676 & 2.77689 & 90.86 & 32 \\
27.7594 & 85.67 & 0.2156 & 3.21379 & 65.76 & 39 \\
46.1762 & 61.90 & 0.2673 & 1.96594 & 47.51 & 33 \\
23.4993 & 36.71 & 0.3329 & 3.78587 & 28.17 & 25 \\
& & & & $152 / 5=30$ \\
\hline
\end{tabular}

Crystalline structure of the AgNPs is; $23+32+39+33+25=30 \mathrm{~nm}$, FWHM: Full width at half maximum, AgNPs: Silver nanoparticles

Table 2: In vitro cytotoxicity assays of AgNPs against human lung cancer cell line (A549) and Breast cancer cell line (MCF 7)

\begin{tabular}{lll}
\hline Compound & $\begin{array}{l}\text { Lung cancer cell } \\
\text { line (A549) }\end{array}$ & $\begin{array}{l}\text { Breast cancer cell } \\
\text { line (MCF 7) }\end{array}$ \\
\hline $\begin{array}{l}\text { Duration with } \\
\text { IC values }\end{array}$ & $\mathrm{IC}_{50}$ values (24 hrs) & $\mathrm{IC}_{50}$ values (24 hrs) \\
AgNPs & $12.95 \pm 0.05 \mu \mathrm{g} / \mathrm{mL}$ & $10.75 \pm 0.05 \mu \mathrm{g} / \mathrm{mL}$ \\
B. papyrifera & $>5000 \mu \mathrm{g} / \mathrm{mL}$ & $>5000 \mu \mathrm{g} / \mathrm{mL}$ \\
Silver nitrate & $5.5 \pm 0.05 \mu \mathrm{g} / \mathrm{mL}$ & $5.8 \pm 0.05 \mu \mathrm{g} / \mathrm{mL}$ \\
\hline
\end{tabular}

AgNPs: Silver nanoparticles, B. papyrifera: Broussonetia papyrifera sulfur containing proteins and the AgNPs interact with these proteins in the cell as well as with the phosphorus containing compounds like DNA. When AgNPs penetrate the organisms cell it outline a low molecular weight region in the midpoint of the organisms to which the bacteria conglomerate; thus, protecting the DNA from the silver ions. The AgNPs preferably show aggression in the respiratory chain, cell division to end with leading cell death. The AgNPs liberate silver ions in the bacterial cells, which increase their bactericidal activity. The potential use of AgNPs, in the field of biomedical needs constant attention that correlates with size and concentration [30-32]. The antibacterial effect is evaluated on their size synthesized. The AgNPs have the larger 


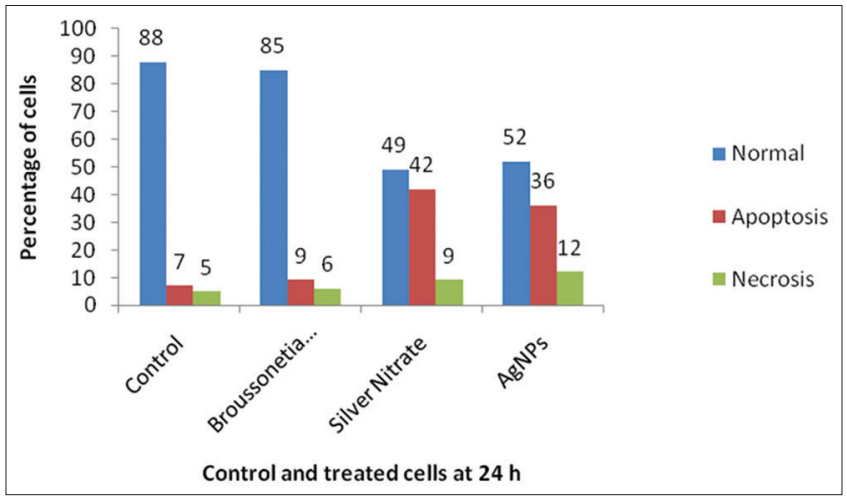

Fig. 5: A549 human lung cancer cell line cytotoxicity

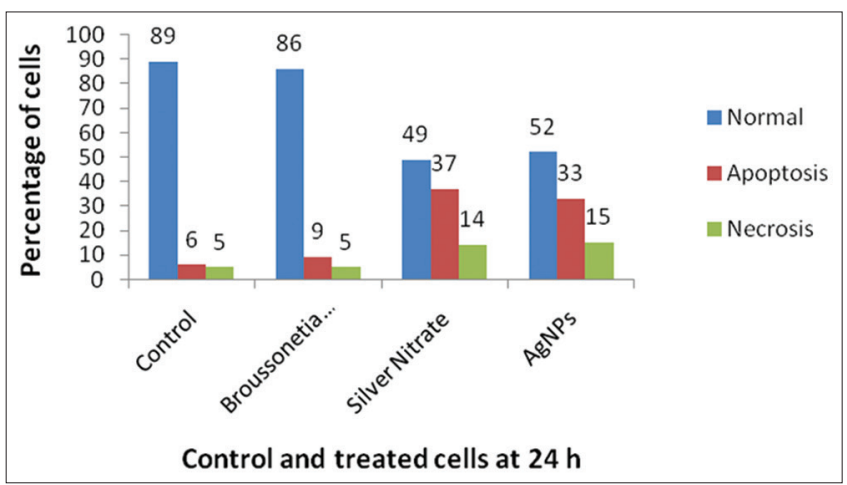

Fig. 6: MCF-7 human breast cancer cell line cytotoxicity

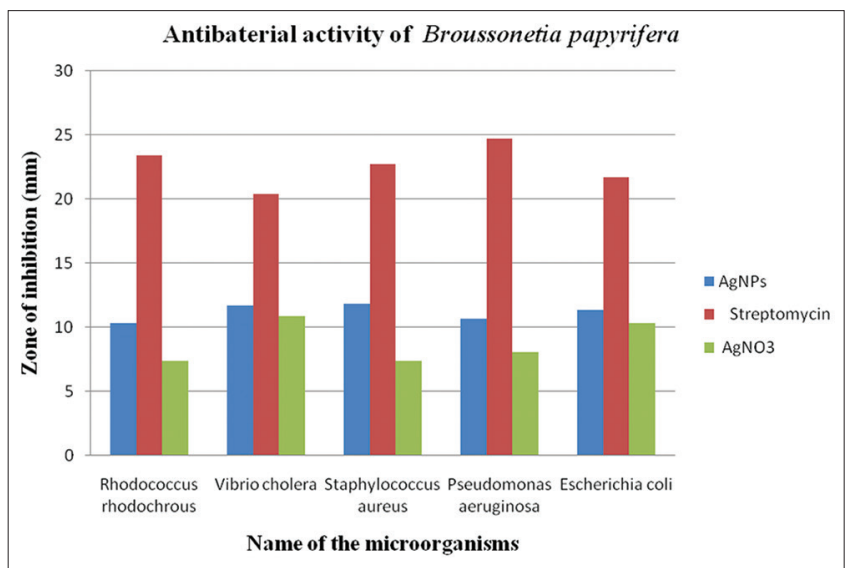

Fig. 7: Graphical representation of comparison of zone of inhibition recorded for silver nanoparticles (Broussonetia papyrifera) against pathogens by agar disc diffusion method

surface area. The antibacterial activity of AgNPs is potent inhibitory activity against clinically isolated pathogens. The drugs derived from herbs may have the possibility of their use in medicine because of their good antibacterial activity. Thus, the AgNPs have the maximum zone of inhibition in the process [33-36]. The bacterial pathogen $R$. rhodochrous showed the maximum zone of inhibition (11.8 \pm 0.447$)$. Synthesized AgNPs operate as an effective antimicrobial agent and proved as an alternative source for the development of new antimicrobial agents to combat the problem of resistance.

\section{CONCLUSION}

The research work at present focused on precisely on the development of AgNPs from plant resource, which is simple, eco-friendly and affordable. The green synthesis method is always

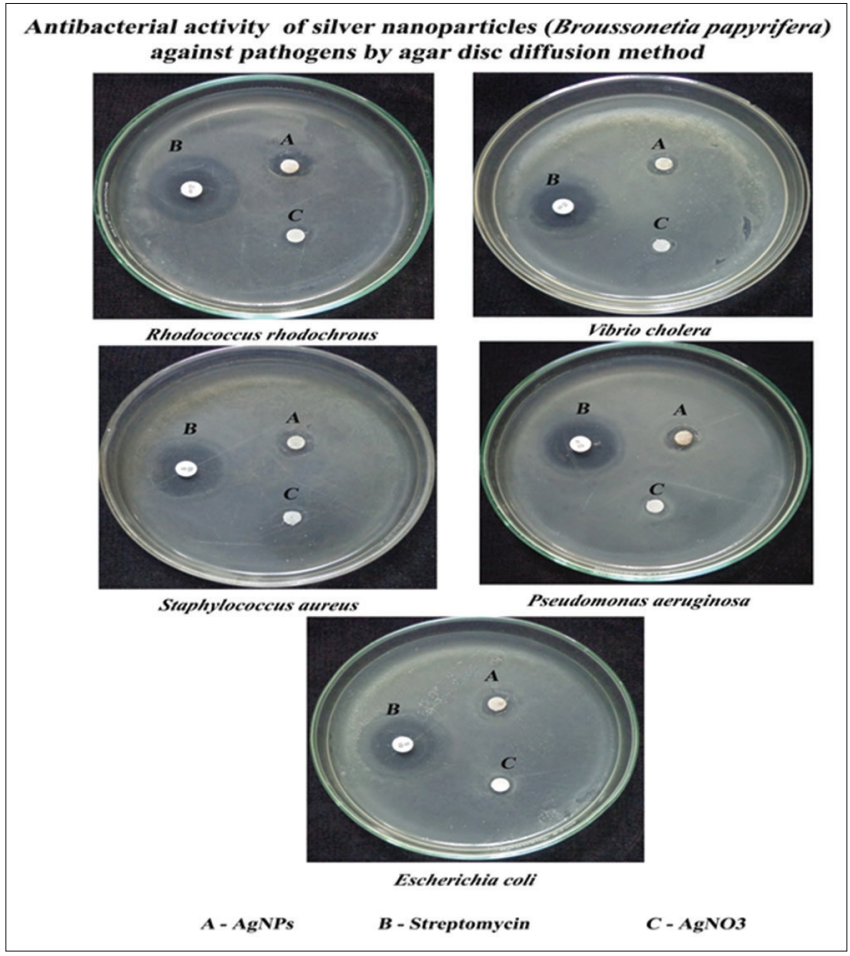

Fig. 8: Zone of inhibition showed by silver nanoparticles (Broussonetia papyrifera) against pathogens

Table 3: Evaluation of antibacterial effects of silver nanoparticles (B. papyrifera) against pathogens by agar disc diffusion method

\begin{tabular}{llll}
\hline \multicolumn{1}{l}{ Test bacteria } & & \multicolumn{2}{l}{ Zone of inhibition } \\
\cline { 1 - 1 } AgNPs & & Streptomycin & AgNO $_{3}$ \\
\hline $11.8 \pm 0.447$ & & $24.66 \pm 1.154$ & $10.8 \pm 0.836$ \\
$10.27 \pm 0.55$ & & $20.33 \pm 2.072$ & $07.34 \pm 6.42$ \\
$10.66 \pm 1.154$ & & $22.66 \pm 1.154$ & $07.33 \pm 6.42$ \\
$11.33 \pm 0.57$ & & $21.66 \pm 1.527$ & $08.00 \pm 6.082$ \\
$10.6 \pm 0.894$ & $23.33 \pm 2.081$ & $09.30 \pm 0.547$ \\
\hline
\end{tabular}

AgNPs: Silver nanoparticles, B. papyrifera: Broussonetia papyrifera

environmentally relevant to this society, because of easy access to this AgNPs by everyone. This research focused on the anticancer activity of AgNPs B. papyrifera. The plants are the major sources and extremely active conventional plant material for the treatment of A549 human lung cancer and MCF-7 human breast cancer. As research progresses, new technologies will aid in the improvement of the anticancer activities of drugs. The cytotoxic efficacy of NPs is predominantly due to their large surface area, which enables efficient drug delivery, and some NPs exhibit anticancer activity. The AgNPs have been produced by B. papyrifera, which is an economical, efficient and eco-friendly process. The zones of inhibition were formed in the antimicrobial screening test indicated, that the AgNPs synthesized in this procedure has the efficient antimicrobial activity against pathogenic bacterial strains. The biologically synthesized AgNPs could be of immense use in the medical field for their efficient antimicrobial function. An understanding about the potential toxicity, dynamics, and route of expulsion from the body will portray realistic aspects on nanostructures precisely in the human health care, thus promising the answers for various untapped queries on use of nanoparticles. Before this application, the due factor of AgNPs should be checked. Therefore, the FESEM, EDAX, and XRD are some of measurable parameters which determine the particles action in the field of biomedical that contributes largely for the betterment of the recent society. 


\section{ACKNOWLEDGMENTS}

The authors are thankful to the Jesuit Administration for their constant support and guidance that they rendered during the course of the research work.

\section{REFERENCES}

1. Jeong SH, Yeo SY, Yi SC. The effect of filler particle size on the antibacterial properties of compounded polymer/silver fibers. J Mater Sci 2005;40(20):5407-11.

2. Prabhu N, Divya TR, Yamuna G. Synthesis of silver phyto nanoparticles and their antibacterial efficacy. Dig J Nanomater Biostruct 2010;5(1):185-9.

3. Marambio-Jones C, Hoek EM. A review of the antibacterial effects of silver nano materials and potential implications for human health and the environment. J Nanopart Res 2010;12(5):1531-51.

4. World Health Organization. Global battle against cancer won't be won with treatment alone. Effective Prevention Measures Urgently Needed to Prevent Cancer Crisis. London, UK: International Agency for Research on Cancer; 2014.

5. Moten A, Schafer D, Farmer P, Kim J, Ferrari M. Redefining global health priorities: Improving cancer care in developing settings. J Glob Health 2014;4(1):010304.

6. Huston MA. Management strategies for plant invasions: Manipulating productivity, disturbance, and composition. Divers Distrib 2004; 10:167-78

7. Malik RN, Husain SZ. Broussonetia papyrifera (L.) L'her. Ex Vent: An environmental constraint on the Himalayan foothills vegetation. Pak J Bot 2007;39(4):1045-53

8. Chauhan R, Kumar A, Abraham J. A biological approach to the synthesis of silver nanoparticles with Streptomyces sp JAR1 and its antimicrobial activity. Sci Pharm 2013;81(2):607-21.

9. Gopinath S, Saha MN, John VJ, Khanum NS, Ganesh S, Patil GM. Biological synthesis, characterization and application of silver nano particles - A review. Int J Pharm Appl 2013;4(1):19-28.

10. Mahmood C, Khodadadi E, Khodadadi E. Green synthesis of silver nanoparticles using oak leaf and fruit extracts (Quercus) and its antibacterial activity against plant pathogenic bacteria. Int J Biosci 2014;4(3):97-103

11. Mubayi A. Evidence based green synthesis of nanoparticles. Adv Mater Lett 2012;3(6):519-25.

12. Mers SS, Kumar ET, Ganesh V. Gold nanoparticles-immobilized, hierarchically ordered, porous $\mathrm{TiO} 2$ nanotubes for biosensing of glutathione. Int J Nanomedicine 2015;10 Suppl 1:171-82.

13. Rajeshkumar S. Synthesis of silver nanoparticles using fresh bark of Pongamia pinnata and characterization of its antibacterial activity against gram positive and gram negative pathogens. Resour Efficient Technol 2016;2(1):30-5

14. Pak ZH, Abbaspour H, Karimi N, Fattahi A. Eco-friendly synthesis and antimicrobial activity of silver nanoparticles using Dracocephalum moldavica seed extract. Appl Sci 2016;6:1-10.

15. Spector DL, Goldman RD, Leinwand LA. Culture and Biochemical Analysis of Cells, Cell: A Laboratory Manual. Vol. 1. New York: Cold Spring Harbor Laboratory Press; 1998. p. 1-34.

16. Mallikarjuna K, Sushma NJ, Narasimha G, Manoj L, Raju BD. Phytochemical fabrication and characterization of silver nanoparticles by using pepper leaf broth. Arabian J Chem 2014;7(6):1099-103.

17. Anandalakshmi K, Venugobal J, Ramasamy V. Characterization of silver nanoparticles by green synthesis method using Pedalium murex leaf extract and their antibacterial activity. Appl Nanosci 2016;6(3):399-408.

18. Magudapatty P, Gangopadhgayrans P, Panigrahi BK, Nair KG, Dharam S. Electrical transport studies of Ag nanoclusters embedded in glass matrix. Physica B 2001;299:142-6.

19. Kaviya S, Santhanalakshmi J, Viswanathan B, Muthumary J,
Srinivasan K. Biosynthesis of silver nanoparticles using citrus sinensis peel extract and its antibacterial activity. Spectrochim Acta A Mol Biomol Spectrosc 2011;79(3):594-8

20. Das S, Das J, Samadder A, Bhattacharyya SS, Das D, Khuda-Bukhsh AR. Biosynthesized silver nanoparticles by ethanolic extracts of Phytolacca decandra, Gelsemium sempervirens, Hydrastis canadensis and Thuja occidentalis induce differential cytotoxicity through G2/M arrest in A375 cells. Colloids Surf B Biointerfaces 2013;101:325-36.

21. Logeswari P, Silambarasan S, Abraham J. Synthesis of silver nanoparticles using plants extract and analysis of their antimicrobial property. J Saudi Chem Soc 2015;19(3):311-7.

22. Krishnaraj C, Muthukumaran P, Ramachandran R, Balakumaran MD, Kalaichelvan PT. Acalypha indica Linn: Biogenic synthesis of silver and gold nanoparticles and their cytotoxic effects against MDA-MB-231, human breast cancer cells. Biotechnol Rep 2014;4(4):42-9.

23. Dwivedi AD, Gopal K. Biosynthesis of silver and gold nanoparticles using Chenopodium album leaf extracts. Colloids Surf A Physicochem Eng Asp 2010;369:27-33.

24. Rutberg FG, Dubina MV, Kolikov VA, Moiseenko FV, Ignat'eva EV, Volkov NM, et al. Effect of silver oxide nanoparticles on tumor growth in vivo. Dokl Biochem Biophys 2008;421:191-3.

25. Kuppurangan G, Karuppasamy B, Nagarajan K, Sekar RK, Viswaprakash N, Ramasamy T. Biogenic synthesis and spectroscopic characterization of silver nanoparticles using leaf extract of Indoneesiella echioides: In vitro assessment on antioxidant, antimicrobial and cytotoxicity potential. Appl Nanosci 2016;6(7):973-82

26. Gurunathan S, Raman J, Abd Malek SN, John PA, Vikineswary S. Green synthesis of silver nanoparticles using Ganoderma neo-japonicumImazeki: A potential cytotoxic agent against breast cancer cells. Int J Nanomedicine 2013;8:4399-413.

27. Park MV, Neigh AM, Vermeulen JP, de la Fonteyne LJ, Verharen HW, Briedé JJ, et al. The effect of particle size on the cytotoxicity, inflammation, developmental toxicity and genotoxicity of silver nanoparticles. Biomaterials 2011;32(36):9810-7.

28. Franco-Molina MA, Mendoza-Gamboa E, Sierra-Rivera CA, Gómez-Flores RA, Zapata-Benavides $\mathrm{P}$, Castillo-Tello $\mathrm{P}$, et al. Antitumor activity of colloidal silver on MCF-7 human breast cancer cells. J Exp Clin Cancer Res 2010;29:148.

29. Jeyaraj M, Sathishkumar G, Sivanandhan G, MubarakAli D, Rajesh M, Arun R, et al. Biogenic silver nanoparticles for cancer treatment: An experimental report. Colloids Surf B Biointerfaces 2013;106:86-92.

30. Kvitek L. Effect of surfactants and polymers on stability and antibacterial activity of silver nanoparticles (NPs). J Phys Chem 2008;112(15):5825-34

31. Patil RS, Kokate MR, Kolekar SS. Bioinspired synthesis of highly stabilized silver nanoparticles using Ocimum tenuiflorum leaf extract and their antibacterial activity. Spectrochim Acta A Mol Biomol Spectrosc 2012;91:234-8.

32. Elkhawas EA, Mohallal ME, Soliman MF. Acute toxicity of different sizes of silver nanoparticles intraperitonally injected in balb/c mice using two toxicological methods. Int J Pharm Pharm Sci 2015;7(2):94-9.

33. Vasanth N, Melchias G, Kumaravel P. Ficus benghalensis mediates synthesis of silver nanoparticles: The green approach yields NPs that are its anti-bacterial and anti-oxidant. World J Pharm Sci 2016;4(7):1-12.

34. Jyoti K, Baunthiyal M, Singh A. Characterization of silver nanoparticles synthesized using Urtica dioica Linn. Leaves and their synergistic effects with antibiotics. J Radiat Res Appl Sci 2016;9(3):217-27.

35. Srinivasan S, Indumathi D, Sujatha M, Sujithra K, Muruganathan U. Novel synthesis, characterization and antibacterial activity of silver nanoparticles using leaf extract of Melothria maderaspatana (Linn) cong. Int J Pharm Pharm Sci 2016;8(6):104-9.

36. Vasanth N, Melchias G, Kumaravel P. Evaluation of silver bio-nanoparticles synthesized with the mediation of Zizyphus jujuba fruit extract on bactericidal compatibility and seed viability. Indo Am J Pharm Res 2016;6:6125-34. 